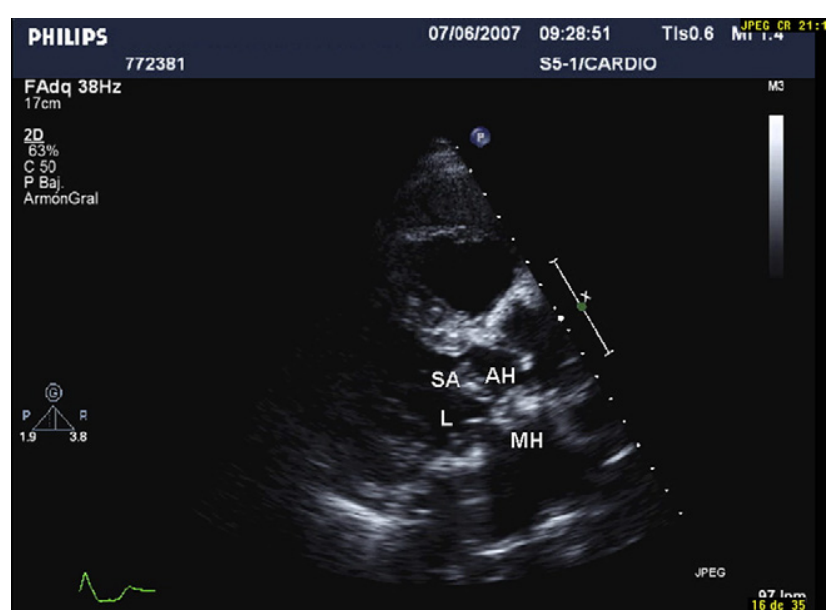

FIGURE 1. Transthoracic diastolic long-axis view. $S A$, Mitral homograft subvalvular apparatus with papillary muscle and chordae tendineae; $A H$, aortic homograft; $L$, mechanical mitral prosthesis leaflets; $M H$, mitral homograft.

substitution of the prosthesis is very poor. ${ }^{2-4}$ In our case, four consecutive reoperations were needed because of recurrent prosthetic dehiscence and mitral valve dysfunction. It was considered that a mitral homograft could be a valid alternative, but functional results were disappointing because of limited mobility and deficient coaptation of the anterior leaflet. Implantation of an annuloplasty ring and repair of the valve commissure were unsuccessful, and instead of explanting the homograft it was decided to remove the annuloplasty ring and insert a bioprosthesis in a transvalvular position, with the homograft acting as a native valve. At 14 months of follow-up, the patient is free of symptoms, and functional results are satisfactory. Hypersensitivity to the suture ring of the valve prosthesis is an appealing explanation for our findings. In this respect, the interposed homograft avoided the potential risk of intolerance to the suture ring and also prevented direct contact between the infected tissue and the prosthesis.

We thank Marta Pulido, MD, for editing the manuscript and for editorial assistance.

\section{References}

1. Revuelta JM, Bernal JM, Rabasa JM. Transvalvular technique for implantation of a mitral valve homograft. J Thorac Cardiovasc Surg. 1996;111:281-2.

2. Echevarria JR, Bernal JM, Rabasa JM, Morales D, Revilla Y, Revuelta JM. Reoperation for bioprosthetic valve dysfunction. A decade of clinical experience. Eur $J$ Cardiothorac Surg. 1991;5:523-7.

3. Pérez-Vázquez A, Fariñas MC, García-Palomo JD, Bernal JM, Revuelta JM, González-Macías J. Evaluation of the Duke criteria in 93 episodes of prosthetic valve endocarditis: could sensitivity be improved? Arch Intern Med. 2000;160:1185-91.

4. Fariñas MC, Pérez-Vázquez A, Fariñas-Alvarez C, García-Palomo D, Bernal JM Revuelta JM, et al. Risk factors of prosthetic valve endocarditis: a case-control study. Ann Thorac Surg. 2006;81:1284-90.

\title{
Concomitant giant coronary artery and coronary sinus aneurysms
}

Basar Sareyyupoglu, MD, James E. Davies, MD, Grace Lin, MD, and Thoralf M. Sundt, MD, Rochester, Minn

Coronary artery aneurysms are uncommon, being noted in $0.15 \%$ to $4.9 \%$ of patients undergoing coronary angiography. Only a small fraction of these aneurysms are of sufficient size to be considered "giant," a term commonly applied when such lesions exceed 20 to $50 \mathrm{~mm}$ in diameter. ${ }^{1,2}$ Coronary artery fistulae are equally rare, reportedly occurring in $0.22 \%$ of patients undergoing cardiac catheterization. $^{3}$ Curiously, the former lesion has been reported

\footnotetext{
From the Cardiovascular Surgery and Cardiovascular Diseases Departments, Mayo Clinical, Rochester, Minn.

Received for publication Nov 13, 2007; accepted for publication Oct 27, 2008.

Address for reprints: Thoralf M. Sundt, MD, Mayo Clinic, Cardiothoracic Surgery Department, Joseph 5-200, 200 First St SW, Rochester, MN 55905 (E-mail: sundt.thoralf@mayo.edu).

J Thorac Cardiovasc Surg 2009;137:763-5

$0022-5223 / \$ 36.00$

Copyright (C) 2009 by The American Association for Thoracic Surgery

doi:10.1016/j.jtcvs.2008.10.021
}

associated with the latter in $30 \%^{2}$ to $80 \%{ }^{1}$ of cases, with communication most often to the left ventricle, ${ }^{1}$ right ventricle, or right atrium. ${ }^{2}$ One such fistula with associated dilatation of the right coronary artery (RCA) but without frank aneurysm has been reported to the coronary sinus (CS). ${ }^{4}$ We recently encountered a case of concomitant giant aneurysms of the proximal RCA and CS, with a distal RCA-CS fistula.

\section{CLINICAL SUMMARY}

An 82-year-old woman was admitted to the hospital with worsening right heart failure. Three years previously, she was incidentally discovered to have a giant RCA aneurysm. Surgical repair was declined at that time by the patient. Because of worsening symptoms of dyspnea on exertion and pedal edema, however, the patient sought evaluation at our institution. She denied angina pectoris. 


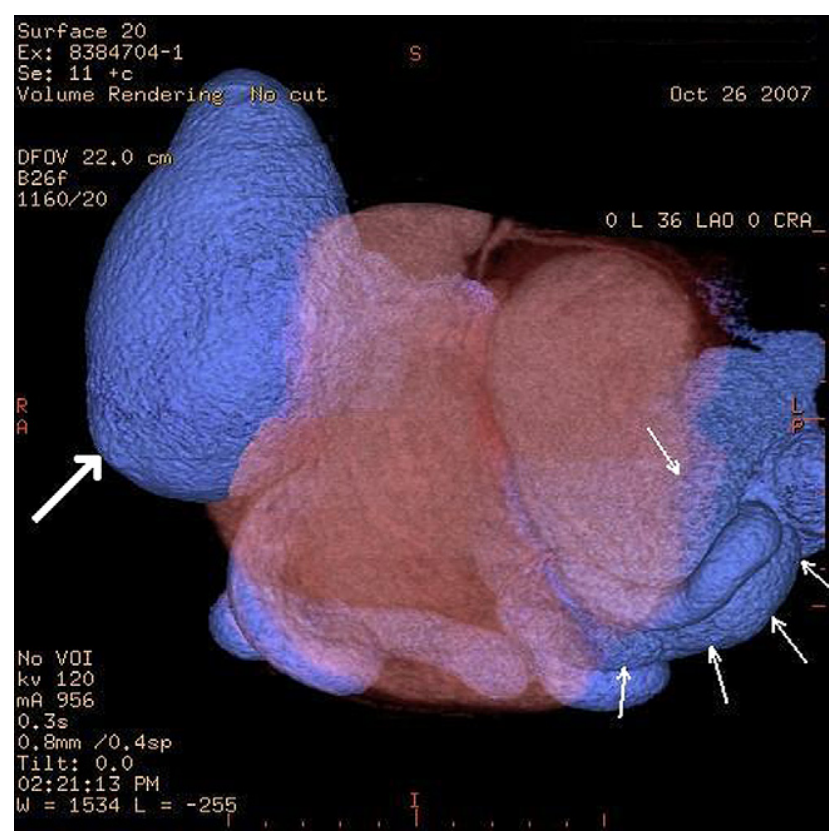

FIGURE 1. Computed tomographic coronary angiogram showing giant right coronary artery aneurysm (big arrow), right coronary artery, and giant coronary sinus aneurysm (small arrows).

Echocardiographic analysis demonstrated normal ventricular function without regional wall motion abnormalities, severe tricuspid regurgitation, and moderate mitral regurgitation with distortion of the mitral annulus by a CS aneurysm. Coronary arteriographic analysis demonstrated a normal left coronary system without occlusive atherosclerotic disease, a giant proximal RCA aneurysm, and a distal RCA-CS fistula. Right heart catheterization demonstrated reversible severe pulmonary hypertension and a $\mathrm{Qp} / \mathrm{Qs}$ ratio of 2.76. In addition, she had severe chronic obstructive pulmonary disease with an $\mathrm{FEV}_{1}$ of 0.64 (34\% of normal value) and a vital capacity 1.01 ( $42 \%$ of normal value). Chest radiographic analysis demonstrated a compression in both lungs because of massively enlarged cardiac silhouette. Computed tomographic analysis demonstrated a giant RCA aneurysm $(8.9 \times 7.6 \times 11.4 \mathrm{~cm})$ and a CS aneurysm $(9 \times 6.8 \times 7.8 \mathrm{~cm})$ without atherosclerotic coronary disease (Figure 1). There was no evidence suggestive of thrombus or dissection of the RCA.

The patient underwent repair on cardiopulmonary bypass with reconstruction of the RCA with an interposition saphenous vein graft excluding the aneurysmal segment. The orifice of the CS opening was stenotic. Two fistulous connections from the distal RCA were identified and oversewn (Figure 2). The narrowed CS ostium was enlarged, and the tricuspid valve was repaired with band annuloplasty. Postoperative echocardiographic analysis showed no other fistula and improvement in the mitral regurgitation to mild. Histopathologically, the aneurysmal wall showed marked intimal atherosclerosis, disruption of the internal elastic

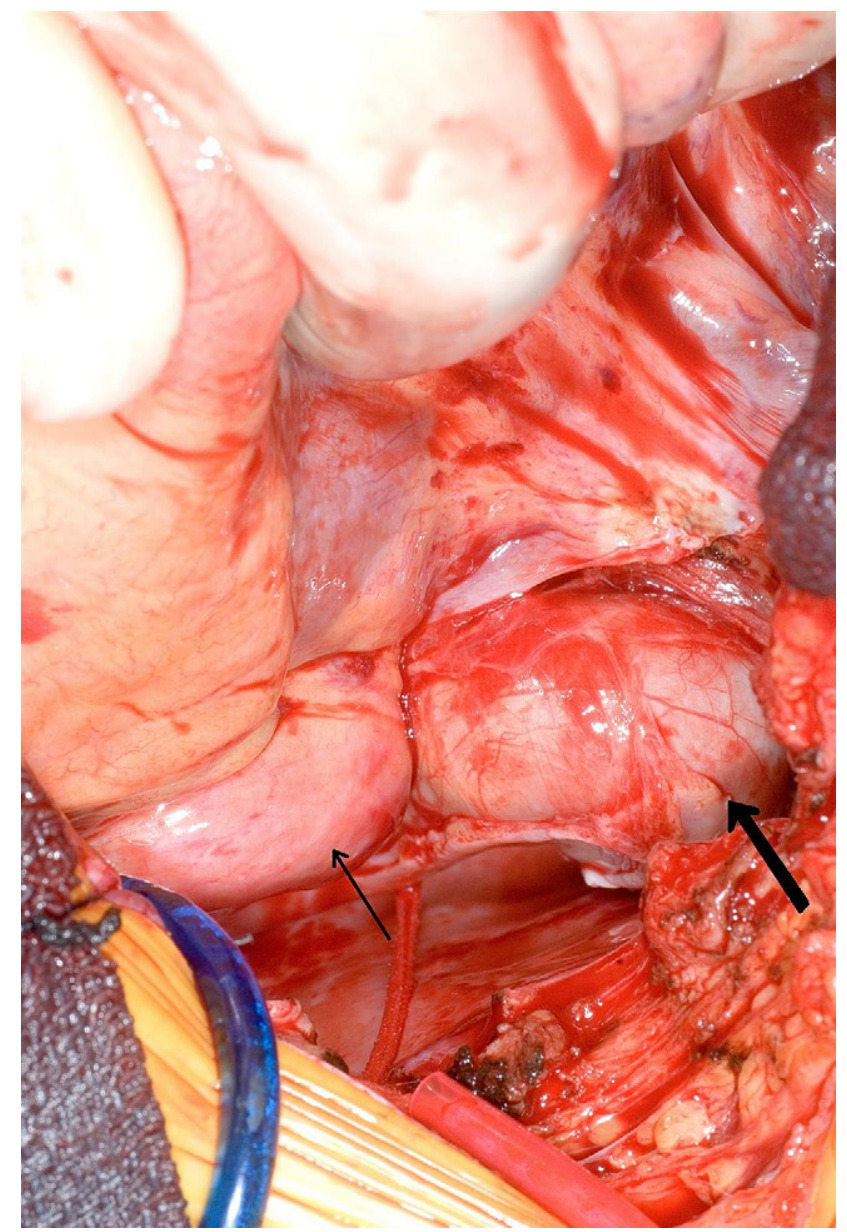

FIGURE 2. At the inferobasal surface of the heart, a right coronary artery (small arrow) and giant coronary sinus aneurysm (big arrow) are seen.

lamina, and moderate medial thinning. The patient was discharged on postoperative day 10 .

\section{DISCUSSION}

Coronary artery aneurysms are most often incidental findings at the time of coronary arteriographic analysis, as are coronary artery fistulae. The indications for repair of both entities are a matter of some controversy, particularly in the asymptomatic patient. Repair of truly giant aneurysms, such as the one in our patient, however, is clearly indicated to prevent rupture. Fortunately, its large size facilitates repair by means of simple interposition grafting, as has been previously suggested by others. ${ }^{5}$

In our case simultaneous repair of the coronary artery fistulae was also indicated on the basis of the large left-to-right shunt and heart failure symptoms, as well as the resultant CS aneurysm that was exerting a mass effect, distorting the mitral annulus. In many cases, particularly in the pediatric population, such fistulae are less clearly symptomatic, and the indications for their repair are less clear. With aging, however, symptoms of angina pectoris and congestive heart 
failure become more common. ${ }^{3}$ It is particularly remarkable that our patient, despite her advanced age and large shunt, had no symptoms of angina pectoris. This is likely thanks to the significant osteal stenosis of the CS, which would have maintained a relatively high intracoronary sinus pressure, minimizing the steal phenomenon from the right coronary system. Although the intracoronary sinus pressure was not measured directly, the degree of aneurysmal dilatation of the CS is indirect evidence of the same.

The cause of this patient's coronary abnormalities is uncertain, although one might presume the fistula to be congenital in origin, with the aneurysm being caused by altered flow dynamics in the RCA. The most common cause of aneurysm of the coronary artery is atherosclerosis; however, the patient had no other atherosclerotic burden in her coronary system. Other possible causes are Kawasaki disease, Takayasu arteritis, systemic lupus erythematosus, polyarteritis nodosa, bacterial infection, septic embolism, and trauma. There was no evidence of these causes in our patient, however.

\section{References}

1. Li D, Wu Q, Sun L, Song Y, Wang W, Pan S, et al. Surgical treatment of giant coronary artery aneurysm. J Thorac Cardiovasc Surg. 2005;130:817-21.

2. Matawari T, Koshino T, Morishita K, Komatsu K, Abe T. Successful surgical treatment of giant coronary artery aneurysm with fistula. Ann Thorac Surg. 2000;70:1394-7.

3. Cheung DL, Au WK, Cheung HH, Chiu CS, Lee WT. Coronary artery fistulas: long-term results of surgical correction. Ann Thorac Surg. 2001;71:190-5.

4. Schmid FX, Elsner D, Merk J, Birnbaum DE. Giant right coronary artery-coronary sinus fistula. Eur J Cardiothorac Surg. 2002;21:929.

5. Firstenberg MS, Azoury F, Lytle BW, Thomas JD. Interposition vein graft for giant coronary aneurysm repair. Ann Thorac Surg. 2000;70:1397-8.

\title{
Rapid extracorporeal life support rescue in patients undergoing the Norwood procedure
}

\author{
Nathalie Roy, MD, ${ }^{\mathrm{a}}$ Ivan M. Rebeyka, MD, ${ }^{\mathrm{a}}$ Joseph Atallah, MD, ${ }^{\mathrm{b}}$ and David B. Ross, MD, ${ }^{\mathrm{a}}$ Edmonton, Alberta, Canada
}

Neonates undergoing the Norwood stage I procedure are susceptible to postoperative hemodynamic instability, low cardiac output, and sudden cardiac arrest. The outcome of rescue extracorporeal life support (ECLS) after the stage I procedure is likely improved when deployment can be achieved in an efficient manner. We describe a simple and rapid technique of arterial cannulation for rescue ECLS using a $3 \mathrm{~mm}$ polytetrafluoroethylene (PTFE) graft based on a technique of selective intraoperative arterial perfusion during the aortic arch reconstruction.

\section{CLINICAL SUMMARY}

The perfusion strategy for the Norwood stage I procedure with a right ventricle-pulmonary artery (RV-PA) shunt ${ }^{1}$ uses an $8 \mathrm{~F}$ arterial cannula (Medtronic, Minneapolis, Minn) inserted within a $3 \mathrm{~mm}$ PTFE graft (W.L. Gore and Associates, Newark, Del) anastomosed to the innominate artery. ${ }^{2}$ A period of low-flow cerebral perfusion at $50 \mathrm{~mL} \cdot \mathrm{kg}^{-1} \cdot \mathrm{min}^{-1}$

\footnotetext{
From the Divisions of Cardiac Surgery, ${ }^{\mathrm{a}}$ and Pediatric Cardiology, ${ }^{\mathrm{b}}$ Stollery Children's Hospital and University of Alberta, Edmonton, Alberta, Canada. Received for publication Nov 21, 2007; accepted for publication Dec 24, 2007. Address for reprints: Nathalie Roy, MD, 2D4.37 Walter C. MacKenzie Centre 8440112 St, Edmonton, Alberta, Canada, T6G 2B7 (E-mail: nroy1@ualberta.ca). J Thorac Cardiovasc Surg 2009;137:765-6 $0022-5223 / \$ 36.00$ Copyright (c) 2009 by The American Association for Thoracic Surgery doi:10.1016/j.jtcvs.2007.12.071
}

is used during the aortic arch repair, followed by a short period of circulatory arrest for the atrial septectomy and at times for the proximal aortic reconstruction. At the end of the procedure, the PFTE graft is occluded at its base with the innominate artery by using a vascular clip and trimmed to a length of $4 \mathrm{~cm}$ (Figure 1). The sternum is stented open with primary skin closure. ${ }^{3}$ If the postoperative period is uneventful, the graft is shortened to a few millimeters at the time of chest closure. In the event Emergency ECLS is required in the postoperative period, the graft is irrigated with a saline solution, the clips are removed, and the arterial cannula is inserted into the graft for systemic perfusion. The cannula is deaired in a retrograde fashion before connecting it to the ECLS circuit.

A 1.6-kg male infant born at 32 weeks of gestation was diagnosis with hypoplastic left heart syndrome with mitral and aortic atresia. He underwent a Norwood stage I procedure with a $5 \mathrm{~mm}$ RV-PA shunt at 6 weeks of life and a weight of $2.5 \mathrm{~kg}$.

The baby had a stable early postoperative period but experienced a cardiac arrest caused by tamponade from a displaced intracardiac line. Rapid arterial cannulation for ECLS was obtained by inserting an $8 \mathrm{~F}$ cannula into the stump of the aforementioned graft used for selective perfusion during the stage I procedure. Venous cannulation was performed through a purse-string suture in the right atrial 